\title{
Discriminação de variedades de citros em imagens CCD/CBERS-2
}

\author{
Discrimination of citrus varieties using CCD/CBERS-2 satellite imagery
}

\author{
Ieda Del' Arco Sanches ${ }^{\text {I }}$ Salete Gürtler ${ }^{\mathrm{II}}$ Antonio Roberto Formaggio ${ }^{\text {I* }}$
}

\section{RESUMO}

\begin{abstract}
O presente trabalho teve o objetivo de avaliar as imagens CCD/CBERS-2 quanto à possibilidade de discriminarem variedades de citros. A área de estudo localizase em Itirapina (SP) e, para este estudo, foram utilizadas imagens CCD de três datas (30/05/2004, 16/08/2004 e 11/09/ 2004). Um modelo que integra os elementos componentes da cena citrícola sensoriada é proposto com o objetivo de explicar a variabilidade das respostas das parcelas de citros em imagens orbitais do tipo CCD/CBERS-2. Foram feitas classificações pelos algoritmos Isoseg e Maxver e, de acordo com o índice kappa, concluiu-se que é possível obterem-se exatidões qualificadas como muito boas, sendo que as melhores classificações foram conseguidas com imagens da estação seca.
\end{abstract}

Palavras-chave: sensoriamento remoto, citros, sensor CCD/ CBERS-2, classificação automática, Isoseg, Maxver.

\section{ABSTRACT}

This paper was aimed at evaluating the possibility of discriminating citrus varieties in CCD imageries from CBERS2 satellite ("China-Brazil Earth Resouces Satellite"). The study area is located in Itirapina, São Paulo State. For this study, three CCD images from 2004 were acquired (May 30, August 16, and September 11). In order to acquire a better understanding and for explaining the variability of the spectral behavior of the citrus areas in orbital images (like as the CCD/ CBERS-2 images) a model that integrates the elements of the citrus scene is proposed and discussed. The images were classified by Isoseg and MaxVer classifiers. According to kappa index, it was possible to obtain classifications qualified as 'very good'. The best results were obtained with the images from the dry season.

Key words: remote sensing, citrus cultivars, CCD/CBERS-2 imagery, automatic classification, Isoseg, Maxver.

\section{INTRODUÇÃO}

O Brasil é um dos maiores produtores de citros e lidera o mercado mundial de suco de laranja. Em 2003, as exportações de suco atingiram US\$ 1,2 bilhão. A laranja é a fruta mais produzida no território nacional e ocupa uma área plantada superior a $800 \mathrm{mil}$ hectares (ASN, 2004). Contudo, verifica-se no Brasil a carência de ferramentas para um monitoramento constante das áreas citrícolas, de forma a favorecer a manutenção desta exploração em níveis internacionalmente competitivos.

O lançamento do satélite CBERS-2, em 21 de outubro de 2003, representa um fato marcante para a comunidade brasileira de sensoriamento remoto, uma vez que os sensores a bordo deste satélite [quais sejam: a Câmara Imageadora de Alta Resolução (CCD), o Imageador por Varredura de Média Resolução (IRMSS) e a Câmara Imageadora de Amplo Campo de Visada (WFI)] são de categorias comparáveis às dos sensores dos satélites Landsat e SPOT. Dessa forma, a avaliação das imagens deste satélite sino-brasileiro para diversos tipos de aplicações agrícolas torna-se fundamental para o Brasil (INPE, 2005).

Por outro lado, o estudo de culturas perenes a partir de imagens orbitais é bastante complexo. Considerando-se uma resolução espacial de 20 metros, as informações de um pixel sobre uma área vinícola, conforme NAERT (1985), caracterizam-se por uma mistura de respostas da vegetação das parreiras, que varia em função do estádio vegetativo e do conteúdo de água nas plantas, da cobertura das entrelinhas e das sombras.

\footnotetext{
Instituto Nacional de Pesquisas Espaciais (INPE), CP 515, 12245-970, São José dos Campos, SP, Brasil. E-mail: formag@dsr.inpe.br * Autor para correspondência.

IIUniversidade de São Paulo (USP/ESALQ), Piracicaba, SP, Brasil.
} 
O estudo de pomares de citros a partir de sensores de resolução espacial equivalente à do TM/ Landsat exige o entendimento de diversos fatores. COVRE (1989) constatou variações na resposta espectral desses alvos em função de alterações no substrato, na altura e porcentagem de cobertura do terreno pelas árvores e das características geométricas da disposição das plantas e das condições de observação do sensor.

Dessa forma, considerando-se a importância de desenvolver a capacidade de gerar estatísticas agrícolas rápidas, precisas e de baixo custo sobre áreas citrícolas, bem como o valor de dispor de tecnologia de sensoriamento remoto para monitorálas convenientemente, o objetivo da presente pesquisa foi avaliar a possibilidade de discriminar variedades de citros a partir de imagens obtidas pela câmara CCD do satélite sino-brasileiro CBERS-2.

\section{MATERIAL E MÉTODOS}

Com o objetivo de poder contar com um conjunto de dados o mais controlado possível, tomouse como área de estudo uma fazenda produtora de citros localizada no município de Itirapina (SP), sendo que a propriedade possui área superior a 1.400 ha, cultivados com diversas variedades de citros: "Baía”, "Lima”, "Lima Verde”, "Murcote”, "Natal”, "Pêra” e "Valência”. O solo em toda a extensão da fazenda é arenoso, em relevo suavemente ondulado, sendo classificado como Neossolo Quartzarênico.

A órbita/ponto do satélite CBERS que abrange a região de estudo é a 156/125 (INPE, 2004). No presente estudo, foram utilizadas as bandas espectrais 2 (verde), 3 (vermelho) e 4 (infravermelho próximo) de três imagens CCD/CBERS-2 com datas de passagem nos dias 30 de maio, 16 de agosto e 11 de setembro de 2004.

Um trabalho de coleta de dados em campo foi realizado em setembro/2004 visando a adquirir informações e medições sobre as variedades de citros cultivadas na propriedade, épocas de plantio dos talhões, tipos de solos, documentação fotográfica da área de estudo e condições gerais das parcelas estudadas.

No software SPRING (CÂMARA et al., 1996), as imagens CCD recortadas das três datas escolhidas foram segmentadas e classificadas. A segmentação foi realizada por crescimento de regiões (BINS et al., 1996; OLIVEIRA, 2002), disponível no SPRING, que usa o classificador ISOSEG (nãosupervisionado) (BINS et al., 1993) para classificar as regiões de uma imagem segmentada.
O classificador supervisionado utilizado foi o MaxVer (Máxima Verossimilhança) (MATHER, 1999), que requer estimativas de algumas características estatísticas das classes às quais os pixels serão alocados. Essas estimativas são obtidas de amostras de treinamento, que servirão de base para a classificação da imagem.

O meio mais comum de expressar a precisão de mapas ou classificações automáticas, conforme STORY \& CONGALTON (1986), é obter a porcentagem da área corretamente classificada, quando comparada com dados de referência ("verdade terrestre"). Dessa forma, primeiramente, foi obtido um mapa com base nas diferentes idades dos talhões de citros e, em seguida, outro mapa baseado nas diferentes variedades, e, a partir desses dois documentos, foi gerada uma referência como verdade terrestre.

Foram feitas tabulações cruzadas (a partir de ferramenta disponível no SPRING, conforme CÂMARA, 1996; INPE, 2004) entre as classificações e a referência, para gerar as matrizes de confusão. Em seguida, foram obtidos a exatidão geral (EG), que é uma estatística derivada da matriz de confusão, e o índice kappa. De acordo com BISHOP et al. (1975), a análise kappa é uma técnica multivariada discreta usada em avaliações de precisão para se determinar estatisticamente se uma matriz de erro é significativamente diferente de outra.

\section{RESULTADOS E DISCUSSÃO}

No trabalho de campo realizado na área de estudo, constatou-se que os talhões de tonalidade mais escura na composição colorida RGB 423 correspondem às variedades "Lima Verde" e "Murcote". Os talhões de cor azulada são áreas que serão futuramente plantadas com citros, e que atualmente estão cobertas por gramíneas. Os talhões plantados em 2002 e 2003 (os mais novos da área estudada) aparecem em cores que variam de azul claro a rosa claro, assim como outros talhões mais antigos que não foram adequadamente adubados nas fases iniciais de desenvolvimento.

O espaçamento entre as plantas pode ser um dos fatores que causam a diferença entre "Lima Verde" e "Murcote”, em relação às demais variedades de citros estudadas. Quanto mais adensadas as plantas, menor é a influência do substrato na composição espectral dos pixels. Além disso, o espaçamento adensado das árvores dentro das linhas de plantio exerce importante influência espectral. Isso porque, para as variedades “Lima Verde” (LV) e "Murcote” (MU), ocorre um entrelaçamento entre os ramos de árvores adjacentes, e, assim, cada linha de plantio produz um 
sombreamento significativo nas entrelinhas. Dessa forma, o elemento "sombra” aumenta sua participação na composição espectral de cada pixel, escurecendo-o.

Outro fator que pode contribuir na diferenciação espectral de variedades de citros é a estrutura das plantas. De acordo com DONADIO et al. (1995), a laranja Baía tem porte grande, copa arredondada e folhagem abundante. A Natal tem porte grande e vigoroso. A Lima possui porte médio a grande, alongado. No caso das variedades Lima Verde e Pêra, as árvores possuem porte médio e galhos mais ou menos eretos. No entanto, o porte das plantas pode variar dependendo do porta-enxerto utilizado.

Quando se deseja avaliar o desempenho de classificações digitais, é necessário dispor de uma verdade terrestre, que, no presente caso, foi gerada a partir de banco de dados disponibilizado pelo proprietário da fazenda utilizada como área de estudo. Por este banco de dados, foi possível obterem-se duas verdades terrestres (referências): uma para idade e outra para variedades. Porém, essa divisão não foi adequada, uma vez que o grau de detalhamento deste banco de dados foi bem maior do que os classificadores conseguiram discriminar. Assim, decidiu-se formar uma referência levando em consideração apenas algumas classes de idade e de variedade, e também agrupando outras classes. A referência final ficou com cinco classes de uso: "Lima Verde" ou "Murcote" (talhões plantados com as variedade "Lima Verde" ou "Murcote”), "Valência” ou "Natal” ou "Pêra" (talhões plantados com as variedades "Valência”, ou "Natal”, ou "Pêra”), diversas (talhões plantados com variedades que não eram "Lima Verde”, "Murcote”, "Valência”, "Natal” e "Pêra”), não-plantado (talhões que não estavam plantados com nenhuma variedade de citros) e plantio novo (talhões que foram plantados em 2002 ou 2003, independentemente da variedade).

Os resultados das classificações Isoseg e MaxVer podem ser observados nas figuras 1(a) e 1(b), respectivamente. As duas classificações da imagem do dia 11 de setembro de 2004 foram consideradas na categoria "boa” pelo índice kappa, e apresentaram valores de exatidão geral (EG) semelhantes entre si e superiores a 50\%. As classificações geradas a partir da imagem do dia 30 de maio de 2004 apresentaram os piores resultados, tendo sido classificados como "ruim" e com EG inferiores a 30\%. O melhor desempenho foi obtido com a imagem do dia 16 de agosto de 2004 e o classificador Isoseg, sendo que a classificação gerada foi qualificada como “muito boa”, de acordo com o índice kappa, e teve valor de EG igual a 71\%. A classificação gerada com o classificador MaxVer e a imagem do dia 16 de agosto de 2004 foi qualificada como “razoável”, com EG igual a 51\%.
De forma geral, houve uma confusão entre a classe plantio novo com diversas e "Valência” ou "Natal” ou "Pêra". Na propriedade estudada, existem alguns talhões que sofreram estresse nutricional e, por isso, as plantas não se desenvolveram adequadamente, o que fez com que os tamanhos das árvores ficassem reduzidos em relação aos de outras árvores de mesma variedade e idade. Assim, as plantas que sofreram estresse nutricional (que correspondem a diversos tipos de variedades de citros) possuem dimensões de copas semelhantes às das plantas jovens, e proporcionam quantidade de sombreamento parecido, o que se reflete no comportamento espectral desses talhões, tornando-os espectralmente semelhantes.

A classificação Isoseg da imagem do dia 16 de agosto de 2004 apresentou o melhor desempenho. Observa-se na figura 1(a) que a classificação em questão só possui quatro das cinco classes de uso. As áreas de plantio novo não foram identificadas. No entanto, pelo fato de a classe plantio novo não ter sido identificada, a confusão entre esta classe e as classes diversas e "Valência" ou "Natal" ou "Pêra” não ocorreu, e como a classe plantio novo representava apenas uma pequena área da propriedade estudada, todos esses fatores fizeram com que esta classificação ficasse mais bem qualificada que as demais.

Para auxiliar na identificação dos fatores que contribuíram para a discordância dos resultados em relação às diferentes datas, foi pesquisada a quantidade de precipitação no período de obtenção das imagens de satélite (IAC-CIIAGRO, 2004). Em maio, época de obtenção da primeira imagem, a precipitação total do mês foi superior a $100 \mathrm{~mm}$. Em agosto e setembro, a precipitação caiu para menos de $10 \mathrm{~mm}$. Com a observação dos dados levantados e os resultados, percebe-se que em períodos mais secos é melhor a separação de variedades de citros.

Nas entrelinhas das plantas de citros, normalmente crescem algumas gramíneas, que, na época chuvosa, possuem maior vigor que na época seca. Em função de o espaçamento dos citros ser grande, há, em geral, uma significativa exposição das entrelinhas.

Considerando-se a proposição de um modelo simplificado de elementos componentes do pixel que interferem na sua resposta espectral, pode-se apresentar o seguinte:

$\mathrm{R}_{\lambda}=\mathrm{f}\{\mathrm{DI}+\mathrm{DS}+\mathrm{SI}+\mathrm{SS}\}$

em que:

$\mathrm{R}_{\lambda}=$ resposta espectral de um pixel, na banda $\lambda$;

$\mathrm{DI}=$ porcentagem de um pixel (no terreno) recoberto por dossel iluminado;

DS = porcentagem de um pixel (no terreno) recoberto por dossel sombreado; 


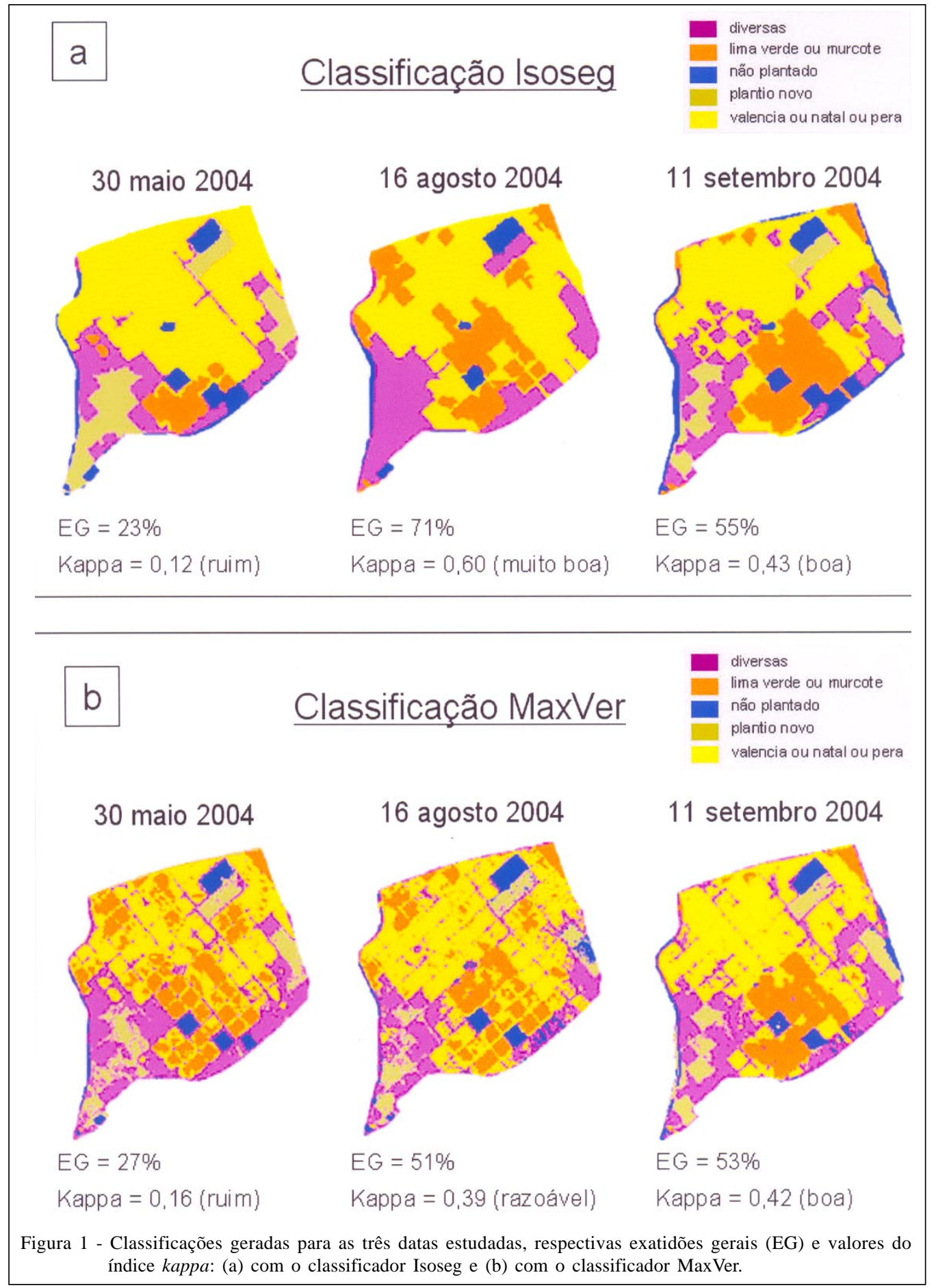

SI = porcentagem de um pixel (no terreno) recoberto por substrato iluminado;

SS = porcentagem de um pixel (no terreno) recoberto por substrato sombreado.

A figura 2 ilustra o esquema de um pixel $20 \mathrm{~m}$ x 20m, como o da câmara CCD/CBERS, em vista superior (a) e também, numa foto local, as proporções dos elementos de radiação de cena (b), modelados pela equação $R_{\lambda}$.

Com relação aos componentes SI e SS (equação $\mathrm{R}_{\lambda}$ ), é importante considerar que a composição do substrato abaixo das plantas de citros é, em geral, constituída de gramíneas verdes, ou de gramíneas secas (palha), ou de solo exposto. Assim, nos meses de maior 


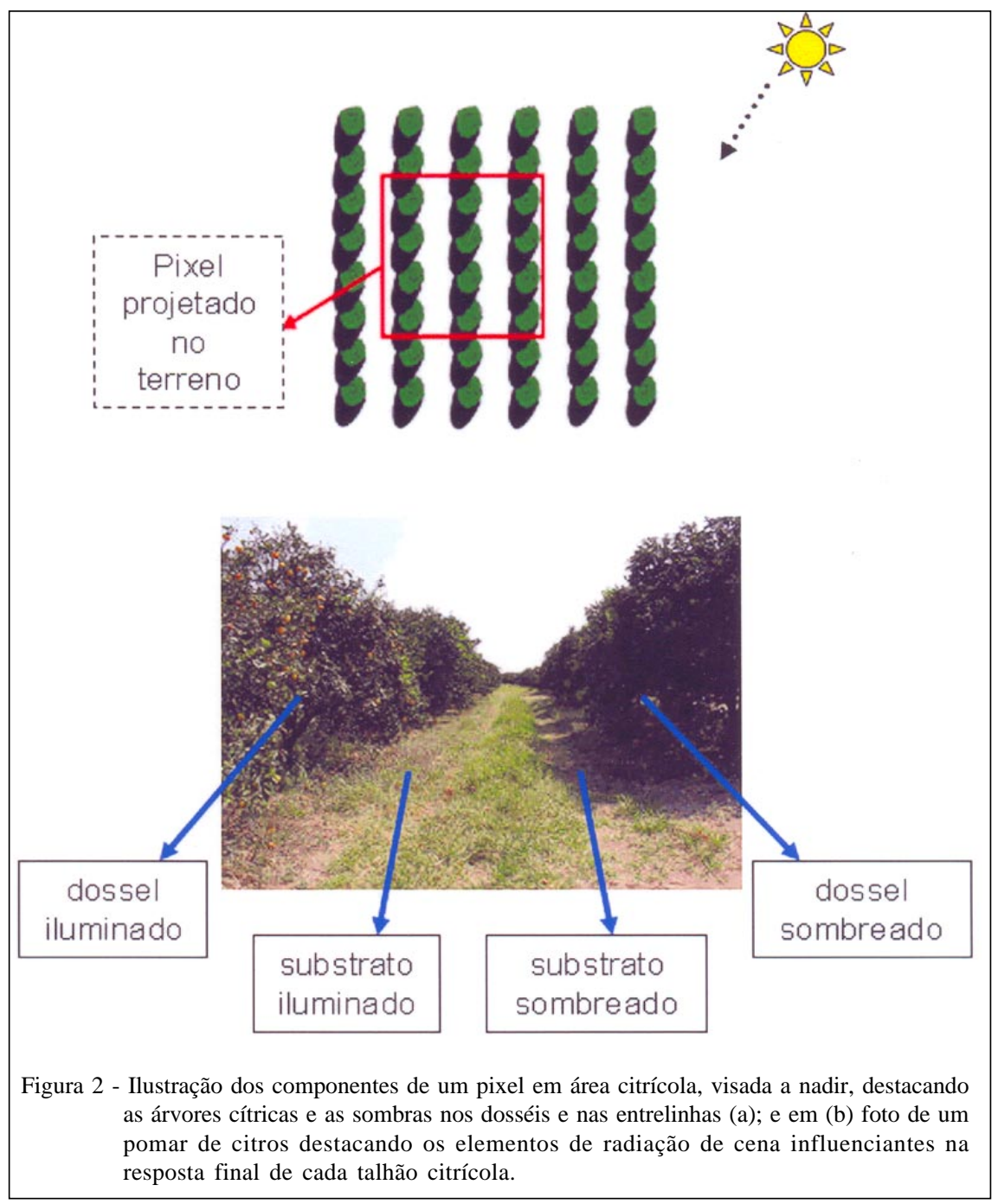

pluviosidade, pode haver maior quantidade de gramíneas verdes e, desta forma, dada a grande exposição das entrelinhas em função do amplo espaçamento entre linhas usado nas áreas de citros, isto faz diminuir a separabilidade entre diferentes variedades.

Nos pomares cítricos no Estado de São Paulo, na época seca, é normalmente feita a gradagem nas entrelinhas, para evitar a competição por água e nutrientes entre as plantas daninhas e as de citros, sendo que, na época chuvosa, a vegetação nas entrelinhas não é retirada, para evitar a erosão, que tende a se tornar mais presente com o aumento da pluviosidade, conforme COVRE (1989). Dessa forma, os manejos aplicados aos talhões e os tipos de substratos subjacentes às plantas de citros desempenham influência significativa e tendem a causar confusão nos resultados de classificações automáticas.
É oportuno indicar ainda que, no presente caso, as áreas estudadas estavam em relevo suave ondulado a plano. Porém, é recomendado que sejam avaliadas áreas citrícolas localizadas em relevos mais ondulados, uma vez que os tipos de substratos, a declividade e a orientação das vertentes devem desempenhar influências significativas na discriminabilidade das áreas plantadas com citros em relação a outras classes adjacentes a elas.

Dada a importância da cultura citrícola, é conveniente realizarem-se avaliações também com sensores orbitais de resoluções da ordem de um ou dois metros, em função do padrão típico da cultura citrícola, verificando-se também aspectos como a potencialidade de discriminarem entre diferentes variedades, idades e manejos. Além disso, é preciso serem desenvolvidos estudos de produtividade, visando preencher importante lacuna quanto às 
metodologias de geração de estatísticas agrícolas e de previsões de safras em níveis municipal, estadual e nacional.

\section{CONCLUSÕES}

Em função das características da área estudada, bem como dos tipos de imagens utilizadas, foi averiguado que é possível discriminarem-se algumas variedades de citros, e que a época seca é a mais indicada para esse tipo de estudo.

A separação das variedades de citros só foi possível após terem sido agrupadas em classes. A variedade Lima Verde foi agrupada com a Murcote; Valência, Natal e Pêra ficaram juntas em uma outra classe; as demais variedades foram colocadas em um mesmo grupo.

Das seis classificações geradas (dois classificadores utilizados e três imagens CCD/CBERS-2 de datas distintas), uma foi considerada, segundo o índice kappa, “muito boa”, duas como "boas”, uma como "razoável”, e duas como "ruins”. O melhor resultado foi obtido com o classificador Isoseg e com a imagem do dia 16 de agosto de 2004, ou seja, da época seca.

\section{REFERÊNCIAS}

AGÊnCIA SEBrae DE NOTíCIAS (ASN). Produção integrada chega à citricultura. 2004. Capturado em 18 out. 2004. Online. Disponível em: <http:// a s n. in t e r jorna l. c o m.br/s i t e/ noticia.. $\mathrm{mf}$ ?noticia $=23004 \&$ canal $=199 \&$ total $=57$ \&indice $=10>$.

BINS, L.S. et al. Um método de classificação não-supervisionada por regiões. In: BRAZILIAN SYMPOSIUM ON GRAPHIC COMPUTATION AND IMAGE PROCESSING, 6., 1993, Recife, PE. Proceedings... Rio de Janeiro: Gráfica Wagner, 1993. V.1 . 386p. p.65-68.

BINS, L.S. et al. Satellite imagery segmentation: a region growing approach. In: SIMPÓSIO BRASILEIRO DE SENSORIAMENTO REMOTO, 8., 1996, Salvador, BA. Anais... São José dos Campos: INPE, 1996. Sessão de Comunicações Técnico-Cientificas. Repositório da URLib:<sid.inpe.br/deise/1999/02.05.09.30>. Capturado em 12 dez. 2005. Online. Disponivel em: <http://iris.sid.inpe.br:1908/ rep/sid. inpe.br/deise/1999/02.05.09.30>.

BISHOP, S.G. et al. Optically induced localized paramagnetic states in chalcogenide glasses. Physical Review Letters, v.34, n.21, p.1346-1350, 1975.
CÂMARA. G. et al. SPRING: integrating remote sensing and GIS by object-oriented data modeling. Computers \& Graphics, v.20, n.3, p.395-403, 1996.

COVRE, M. Influência de parâmetros culturais de citros sobre os dados TM/Landsat. 1989. 241f. (INPE-4856TDL/367). Dissertação (Mestrado em Sensoriamento Remoto) - Instituto Nacional de Pesquisas Espaciais, São José dos Campos.

DONADIO, L.C. et al. Variedades cítricas brasileiras. Jaboticabal: FUNEP, 1995. 228p.

INSTITUTO AGRONÔMICO DE CAMPINAS CENTRO INTEGRADO DE INFORMAÇÕES AGROMETEOROLÓGICAS - IAC - CIIAGRO. CIIAGRO ONLINE: Resenha Agrometeorológica. 2004. Capturado em 19 jan. 2005. Online. Disponível em: <http:// www.iac.sp.gov.br/New/ ciiagro/>.

INSTITUTO NACIONAL DE PESQUISAS ESPACIAIS (INPE). CBERS-2. 2005. Capturado em 9 nov. 2005. Online. Disponível em: <http://www.cbers.inpe.br/en/index_en.htm/>.

Sistema de processamento de informações georeferenciadas - SPRING 4.1 - Tutoriais. 2003. Capturado em 15 set. 2004. Online. Disponível em: http:// www.dpi.inpe.br/spring/portugues/tutorial/index.html

INSTITUTO NACIONAL DE PESQUISAS ESPACIAIS DIVISÃO DE GERAÇÃO DE IMAGENS DO (INPE -DGI). Catálogo de Imagens CBERS. 2004. Capturado em 24 set. 2004. Online. Disponível em: <http://www.dgi.inpe.br/ CDSR/>.

MATHER, P.M. Computer processing of remotely-sensed images: an introduction. Chichester: John Wiley \& Sons, 1999. 292p.

NAERT, B. Caracterisation de la signature spectrale, spatiale et temporale de vignes et vergers - aplication a la teledetection du sol et de la culture. In: INTERNATIONAL COLLOQUIUM ON SPECTRAL SIGNATURES OF OBJECTS IN REMOTE SENSING. 1985, Les Arcs, France. Proceedings... Montfaver: INRA, 1985. p.467-474. (ESA SP-247).

OLIVEIRA, J.C. Indice para avaliação de segmentação (IAVAS): uma aplicação em agricultura. 2002. $160 \mathrm{f}$. (INPE-9554-TDI/830). Dissertação (Mestrado em Sensoriamento Remoto) - Deposited in the URLib collection. São José dos Campos. 2002. Disponível na biblioteca digital. Acesso em: 11 dez. 2005. Online. URLib:<http:// iris.sid.inpe.br:1912/rep-/sid.inpe.br/marciana/2003/03.05. $15.25>$.

STORY, M.; CONGALTON, R.G. Accuracy assessment: a user's perspective. Photogrammetric Engineering and Remote Sensing, v. 52, n. 3, p. 397-399, 1986. 